\title{
Therapeutic bullfrog oil-based nanoemulsion for oral application: Development, characterization and stability
}

RENATA RUTCKEVISKI ${ }^{1,2}$

FRANCISCO HUMBERTO XAVIER-JR ${ }^{2}$

ANDREZA ROCHELLE DO VALE MORAIS ${ }^{2,3}$

LUCAS AMARAL-MACHADO ${ }^{2,4}$

EVERTON DO NASCIMENTO ALENCAR 2.3

JULIETA GENRE 2,4

ADRIANO ANTUNES DE SOUZA ARAUJO ${ }^{5}$

ERYVALDO SOCRATES TABOSA DO EGITO ${ }^{1,2,3,4^{*}}$

${ }^{1}$ Universidade Federal do Rio Grande do Norte (UFRN), Programa de Pós-graduação em Ciências Farmacêuticas, Departamento de Farmácia, 59010-180, Natal-RN, Brazil

${ }^{2}$ UFRN, Laboratório de Sistemas Dispersos (LaSiD), Departamento de Farmácia 59010-180, Natal-RN, Brazil

${ }^{3}$ UFRN, Programa de Pós-graduação em Nanotecnologia Farmacêutica, LaSiD Departamento de Farmácia, 59010-180 Natal-RN, Brazil

${ }^{4}$ UFRN, Programa de Pós-graduação em Ciências da Saúde, LaSiD, Departamento de Farmácia, 59010-180, Natal-RN, Brazil

${ }^{5}$ Universidade Federal de Sergipe

Departamento de Farmácia. 49100-000

São Cristovão-SE, Brazil

Accepted July 9, 2018

Published online August 29, 2018
The aim of this study was to develop, optimize, and characterize a stable therapeutic bullfrog oil based nanoemulsion for oral application using a rational experimental design approach. The optimized oral nanoemulsion contained $0.2 \%$ sodium benzoate and $0.02 \%$ propyl-paraben as preservatives; $0.1 \%$ sucralose and $0.4 \%$ acesulfam $\mathrm{K}$ as sweeteners and $0.1 \%$ tutti-frutti as flavoring to mask the unpleasant organoleptic characteristics of bullfrog oil. The oral O/W-nanoemulsion showed the droplet size, PDI, zeta potential, and $\mathrm{pH}$ of $410 \pm 8 \mathrm{~nm}, 0.20 \pm 0.02$, $-38 \pm 2.5 \mathrm{mV}$, and $6.43 \pm 0.05$, respectively. The optimized oral nanoemulsion showed a milky single-phase and optimal physical stability at $25^{\circ} \mathrm{C}$ for 90 days. Indeed, higher oxidation induction time and lower formation of peroxides in the oral nanoemulsion were responsible for improving its stability. A therapeutic delivery system containing bullfrog oil for oral application was successfully developed and optimized with ideal thermo-oxidative stability.

Keywords: bullfrog oil, nanoemulsion, thermo-oxidative stability, experimental design, oral application, therapeutic nanosystem

Nanoemulsions are widely used in the pharmaceutical and food industries owing to their ability to modify organoleptic and rheological properties of active compounds and promote the delivery of therapeutic agents (1). Emulsified systems are able to solubilize both polar and non-polar substances due to the arrangement consisting of small droplets of one liquid dispersed in another immiscible liquid (2). These colloidal dispersions are thermo-

\footnotetext{
*Correspondence; email: socrates@ufrnet.br, socratesegito@gmail.com
} 
dynamically unstable and show a variety of instability mechanisms. In consequence, increased kinetic stability can be achieved by using pharmaceutical excipients such as surfactants (3). Nanoemulsion-based delivery systems encapsulating lipophilic compounds, such as animal oils, show the potential to improve absorption of fatty acids due to a large lipid-water interface (4). Furthermore, these emulsified systems are convenient as they reduce unpleasant animal oil smells, responsible for low patient compliance (5).

In this way, natural animal oils became an interesting alternative source for the development of new products, thanks to their complex mixture of compounds and wide consumer interest in natural products (6). Application of biotechnology in the waste management process of the amphibian Rana catesbeiana Shaw adipose tissue, generally discarded during food processing, produces bullfrog oil and reduces negative environmental impacts. The rich unsaturated fatty acid composition of bullfrog oil, mainly eicosapentaenoic acid, makes it nutritionally and pharmacologically favorable for pharmaceutical applications (7). Intake of eicosapentaenoic acid (EPA; 20:5n-3) has a variety of well-established beneficial effects on human health in preventing and alleviating pathological conditions such as cardiovascular (8), allergy, inflammatory (9) and circulatory diseases (10) and in cancer therapy (11). Recent studies have demonstrated that a simple nanoemulsion containing bullfrog oil showed anti-biofilm activity against certain microorganisms, and also reduced the viability of melanoma cells B16F10 $(12,13)$.

In a previous study, the thermo-oxidative stability of natural bullfrog oil in association with synthetic antioxidants was analyzed due to the easy oxidation of unsaturated fatty acids in bulk media. Thus, the addition of butylhydroxytoluene was required to maintain the thermo-oxidative stability of natural oil (7). However, the large surface area interface during the development of a bullfrog oil based nanoemulsion can also induce interactions between lipids and water-soluble pro-oxidants, reducing the oil quality and producing harmful compounds (14). Therefore, rational thermo-oxidative approaches to producing bullfrog oil based colloidal dispersions should be applied while taking into account the physicochemical stability of the therapeutic oil loaded nanoemulsions.

In this context, the aim of the present study was to develop an original therapeutic bullfrog oil based nanoemulsion for oral application with higher physicochemical stability. To achieve this goal, a rational $2^{3}$ full factorial design was applied in order to obtain a suitable oral nanoemulsion improving its organoleptic attributes, conservation, and stability. Then, thermal and oxidative stabilities of the bullfrog oil based nanoemulsion were evaluated by the peroxide value, conjugated dienes, oxidation induction time, and thermogravimetry analysis.

\section{EXPERIMENTAL}

\section{Material}

Bullfrog adipose tissue was provided by Asmarana Produtos Naturais (Brazil). Span ${ }^{\circledR}$ 80 (sorbitan monooleate 80), acetic acid, chloroform and isooctane were purchased from Sigma Aldrich Inc. (USA). Propylene glycol, Tween ${ }^{\circledR} 20$ (polyoxyethylene 20 sorbitan monolaurate), n-hexane, sodium hydroxide, potassium hydroxide, diethyl ether, hydrochloric acid and sodium carbonate were from VETEC (Brazil). Xanthan gum, propylparaben, methylparaben, sodium benzoate and flavoring came from Via Farma (Brazil). Butylated 
hydroxytoluene (BHT) and butylated hydroxyanisole (BHA) were provided by Labsynth (Brazil). Acesulfame K, aspartame and sucralose were purchased from Valdequímica (Brazil). All chemicals were of analytical or reagent grade and were used without further purification. Ultrapure water was obtained from a water purification system (Milli- $\mathrm{Q}^{\circledR}$ plus, USA) with resistivity and total organic carbon of $16.3 \mathrm{M} \Omega \mathrm{cm}$ and $2 \mathrm{ppm}$ at $25^{\circ} \mathrm{C}$, respectively.

\section{Extraction and characterization of bullfrog oil}

Extraction and characterization of bullfrog oil were conducted according to Rutckeviski et al. 2017 (10). Briefly, the bullfrog adipose tissue was heated on a hot plate at $70 \pm 1{ }^{\circ} \mathrm{C}$ for 30 min under constant stirring (IKA ${ }^{\circledR}, \mathrm{RH}$ basic model KT/C, Germany). The sample was filtered through a $0.22 \mu \mathrm{m}$ membrane filter (Millex ${ }^{\circledR}$, Millipore, France). The main bullfrog oil composition was analyzed by Gas-Chromatography Ultra equipped with an ITQ Tune mass selective detector (Thermo Scientific, USA) after derivatization with the BSTFA reagent. The GC-MS injector was set at $250^{\circ} \mathrm{C}$ and the column was set at $90^{\circ} \mathrm{C}$ with a heating ramp at $2{ }^{\circ} \mathrm{C} \mathrm{min}{ }^{-1}$ to $150{ }^{\circ} \mathrm{C}$, then isothermal heating at $20^{\circ} \mathrm{C} \mathrm{min}^{-1}$ to $300{ }^{\circ} \mathrm{C}$. The volume of the sample injected was $1 \mu \mathrm{L}$ and helium $\left(1 \mathrm{~mL} \mathrm{~min}^{-1}\right)$ was used as the carrier gas.

\section{Development of the control nanoemulsion}

The oil in water $(\mathrm{O} / \mathrm{W})$ bullfrog oil based control nanoemulsion was produced using the phase inversion technique according to a previous study of the pseudo-ternary phase diagram using the required hydrophile-lipophile balance (HLB) established at 12.1, made by our team (13). The choice of the surfactant blend and their ratio was also based on this study. Briefly, the HLB of bullfrog oil was determined based on the development of systems containing $92 \%$ distilled water, $5 \%$ bullfrog oil, and $3 \%$ surfactant blends at different ratio (Tween ${ }^{\circledR} 20$ and Span ${ }^{\circledR} 80$ ). The HLB of the surfactant blend ranged from 4.5 to 15.5, with intervals of 1.0 (first batch) and 0.1 (second batch). The systems were physicochemically analyzed for 60 days and the critical HLB was established as 12.1 (13). Thereafter, a pseudo-ternary phase diagram based on the water titration method was developed using Tween ${ }^{\circledR} 20$ and Span $^{\circledR} 80$ at a ratio of $6.29: 3.71$ in order to obtain the different colloidal phases (13). The nanoemulsion was selected from the milky single-phase region, with the highest oil and lower surfactant concentrations. Thus, the control nanoemulsion was composed of $14 \%(\mathrm{~m} / \mathrm{m})$ of bullfrog oil, $6 \%(\mathrm{~m} / \mathrm{m})$ of surfactant blend (Tween ${ }^{\circledR} 20$ : $\left.\operatorname{Span}^{\circledR} 8063: 37\right)$ and $80 \%(\mathrm{~m} / \mathrm{m})$ of deionized water. For nanoemulsion production, aqueous and oily phases were heated separately at $70{ }^{\circ} \mathrm{C}$ and, thereafter, the aqueous phase was poured into the oil phase under constant stirring using an Ultra-Turrax ${ }^{\circledR}$ T-18 (IKA, Staufen, Germany) at 11,000 rpm for $10 \mathrm{~min}$. The obtained nanoemulsion was cooled down at room temperature, and stored at $25^{\circ} \mathrm{C}$ for 24 hours before characterization.

\section{Experimental design approach to optimize the oral nanoemulsion}

A $2^{3}$ full-factorial experimental design was used to optimize the production of the oral bullfrog oil based nanoemulsion. All tests were randomly performed to ensure the independence of observations and errors. All systems were prepared as described for the con- 
R. Rutckeviski et al.: Therapeutic bullfrog oil-based nanoemulsion for oral application: Development, characterization and stability, Acta Pharm. 69 (2019) 33-48.

Table I. Variables and levels chosen to define the experimental region and their corresponding coded values for the bullfrog oil oral nanoemulsion production

\begin{tabular}{|c|c|c|c|}
\hline & Independent variables & \multicolumn{2}{|c|}{ Level $(\%, m / m)$} \\
\hline $\mathrm{i}$ & $X_{i}$ & -1 & +1 \\
\hline 1 & Flavoring & Tutti-frutti flavors 0.1 & Pineapple flavors 0.1 \\
\hline \multirow{2}{*}{2} & \multirow{2}{*}{ Sweetener } & Aspartame 0.4 & Sucralose 0.1 \\
\hline & & Acesulfame K 0.4 & Acesulfame K 0.4 \\
\hline \multirow{3}{*}{3} & \multirow{2}{*}{ Preservative } & Methylparaben 0.18 & Sodium benzoate 0.2 \\
\hline & & Propylparaben 0.02 & Propylparaben 0.02 \\
\hline & Dependent variables & \multicolumn{2}{|c|}{ Desired response } \\
\hline 1 & Droplet size (nm) & \multicolumn{2}{|c|}{ Minimize } \\
\hline 2 & Zeta potential (mV) & \multicolumn{2}{|c|}{ Maximize } \\
\hline 3 & $\mathrm{pH}$ & \multicolumn{2}{|c|}{ Maximize } \\
\hline
\end{tabular}

trol nanoemulsion, with slight modifications. In the aqueous phase, $5 \%(\mathrm{~m} / \mathrm{m})$ of propylene glycol and $0.3 \%(\mathrm{~m} / \mathrm{m})$ of xanthan gum were added, while in the oily phase $0.01 \%(\mathrm{~m} / \mathrm{m})$ of butylhydroxytoluene (BHT) was added. For the production of the oral nanoemulsion, three independent variables were included: flavoring $(x 1)(0.1 \%(\mathrm{~m} / \mathrm{m})$ of tutti-frutti flavor or $0.1 \%(\mathrm{~m} / \mathrm{m})$ of pineapple flavor), sweetener $(\mathrm{x} 2)(0.4 \%(\mathrm{~m} / \mathrm{m})$ of aspartame/ $0.4 \%(\mathrm{~m} / \mathrm{m})$ of acesulfame K or $0.1 \%(\mathrm{~m} / \mathrm{m})$ of sucralose $/ 0.4 \%(\mathrm{~m} / \mathrm{m})$ of acesulfame K and preservative (x3) $(0.18 \%(\mathrm{~m} / \mathrm{m})$ of methylparaben/ $0.02 \%(\mathrm{~m} / \mathrm{m})$ of propylparaben or $0.2 \%(\mathrm{~m} / \mathrm{m})$ of sodium benzoate $/ 0.02 \%(\mathrm{~m} / \mathrm{m})$ of propylparaben) were selected for the optimization approach. The experimental matrix consisted of 8 runs and each factor was studied between the lower $(-1)$ and the higher (+1) level (Table I). Droplet size, zeta potential and $\mathrm{pH}$ were selected as dependent output response variables in order to obtain a small droplet, negatively charged, and $\mathrm{pH}$-compatible for oral nanoemulsions. The effects of the studied variables were interpreted by the Statistic software (Version 7.0, StatSoft Inc., USA).

\section{Characterization of nanoemulsions}

Macroscopic aspect. - Macroscopic aspects (changes in color and odor) as well as immediate stability (creaming index or phase separation) were evaluated by visual inspection of control and oral nanoemulsions stored in scintillation vials at $25 \pm 2{ }^{\circ} \mathrm{C}$.

$\mathrm{pH}$ determination. - The $\mathrm{pH}$ values were determined in triplicate directly in the nanoemulsions using a pre-calibrated $\mathrm{pH}$-meter (Tecnal, TEC-2, Brazil) at $25 \pm 2{ }^{\circ} \mathrm{C}$.

Conductivity determination. - Conductivity values of the nanoemulsions were determined in triplicate using a pre-calibrated conductimeter (Digimed, DM-32, Brazil) at $25 \pm$ $2{ }^{\circ} \mathrm{C}$. 
Droplet size distribution. - The hydrodynamic diameter and the polydispersity index (PDI) of oil droplets were determined by dynamic light scattering (DLS) using a Zetasizer Nano ZS (Malvern Instruments Ltd, UK). Measurements were conducted at $25^{\circ} \mathrm{C}$ and the samples were diluted at 1:50 with deionized water before analysis.

Zeta potential. - Zeta potential of the nanoemulsion was deduced from the electrophoretic mobility of the particles measured by Laser Doppler Electrophoresis, Zetasizer Nano $\mathrm{ZS}$, at $25^{\circ} \mathrm{C}$ in a $\mathrm{NaCl}$ solution $(1 \mathrm{mM})$ after suitable dilutions $(1 / 50(\mathrm{~V} / \mathrm{V}))$ of the different nanoparticle suspensions. Values are presented as the means of measurements performed on three replicate samples.

\section{Stability studies}

Stability under storage (long-term stability). - Test tubes containing control and basic bullfrog oil based nanoemulsions were stored vertically in a hot air oven at $45 \pm 2$ and 25 $\pm 2{ }^{\circ} \mathrm{C}$. Macroscopic aspects were evaluated weekly for 90 days, following the international regulatory standards of the World Health Organization "Stability testing of active pharmaceutical ingredients and finished pharmaceutical products" (15).

Freeze/thaw stability. - Nanoemulsions were subjected to alternate six freeze and thaw cycles for a period of 12 days. $10 \mathrm{~g}$ of nanoemulsions were stored in sealed tubes for $24 \mathrm{~h}$ in a freezer at $-5^{\circ} \mathrm{C}$, followed by another period of $24 \mathrm{~h}$ at $45^{\circ} \mathrm{C}$ according to Xavier-Júnior et al. (16). After each cycle, the macroscopic aspect was analyzed as described above (2.5.1.)

Stability under centrifugation. - Glass vials containing $5 \mathrm{~g}$ of samples were centrifuged at 3,000 g for $30 \mathrm{~min}$ at $25{ }^{\circ} \mathrm{C}$. Nanoemulsions were evaluated visually, taking physical stability into account.

Oxidative stability. - Formation of primary oxidation products was monitored by formation of peroxide compounds (10). To study the susceptibility to oxidation of the control and the oral bullfrog oil based nanoemulsions, samples were subjected to an accelerated oxidation test under standardized conditions. Immediately after preparation, $60 \mathrm{~g}$ of nanoemulsions were placed into $125 \mathrm{~mL}$ flasks, which were kept sealed and subjected to the Schaal oven test conditions $\left(60^{\circ} \mathrm{C}\right)$. After that, the peroxide value, conjugated dienes and oxidation induction time were analyzed to determine oxidation of the bullfrog oil-based nanoemulsions.

\section{Peroxide value}

$3.5 \mathrm{~g}$ of nanoemulsions were vigorously dissolved in $35 \mathrm{~mL}$ of glacial acetic acid/isooctane $(60: 40(V / V))$. Then, $900 \mu \mathrm{L}$ of saturated potassium iodide solution were added and the sample was titrated with $0.1 \mathrm{~mol} \mathrm{~L}^{-1}$ sodium thiosulfate using starch solution as indicator. Peroxide value was expressed as $\mathrm{mEq}$ of oxygen per 1 kilogram of nanoemulsion.

\section{Conjugated dienes}

The first stage of bullfrog oil oxidation was monitored by conjugated dienes. $0.5 \mathrm{~g}$ of nanoemulsions were diluted in $4 \mathrm{~mL}$ of chloroform/methanol (2:1) under vigorous vortex 
stirring for $12 \mathrm{~min}$. Samples were then centrifuged at 3,500 rpm for $5 \mathrm{~min}$ and the organic phase was removed. Absorbance was measured with an N Evolution 60S UV-Vis Spectrophotometer (Thermo Scientific, USA) at $232 \mathrm{~nm}$ against a blank solution of hexane.

\section{Oxidation induction time}

Oxidation induction time of the nanoemulsions was evaluated by a Rancimat ${ }^{\circledR}(\mathrm{Me}-$ trohm model 873 , Switzerland). Samples were heated at $110 \pm 1^{\circ} \mathrm{C}$ under airflow of $10 \mathrm{~L} \mathrm{~h}^{-1}$. Volatile acid compounds produced during oxidation were analyzed in a conductivimetric cell containing water. Conductivity changes over time were plotted to determine the oxidation induction time of the nanoemulsions.

\section{Thermal stability}

Thermal stability of the nanoemulsions was measured by DTA/TGA (DTG-60H, Shimadzu Corporation, Japan). Samples $(2 \pm 0.5 \mathrm{mg})$ were placed into aluminum pans and analyzed under the heating rate of $10{ }^{\circ} \mathrm{C} \mathrm{min}^{-1}$, nitrogen flow of $50 \mathrm{~mL} \mathrm{~min}{ }^{-1}$ and temperature range of $25-600^{\circ} \mathrm{C}$.

\section{Statistical analyses}

All results were expressed as mean \pm standard deviation of the analysis in triplicate. Statistical comparisons were made using the analysis of variance (ANOVA). Comparisons between two groups were made by Student's $t$-test. Differences were considered statistically significant at $p<0.05$. Graph Pad Prism (Version 5.0, USA) software was used for statistical analysis of the data.

\section{RESULTS AND DISCUSSION}

\section{Extraction and chemical composition of bullfrog oil}

The bullfrog oil extraction process gave a yield of $60 \pm 0.9 \%(\mathrm{~m} / \mathrm{m})$ with the absence of solvent residues that could have negative impacts on human health (7). Bullfrog oil showed ideal physicochemical characteristics for the production of therapeutic nanoemulsions without off-flavors and with low peroxide and acidity values (7). According to the GC-MS analysis, the main compounds found in bullfrog oil were oleic acid (18:1 n-9) (30\%), eicosapentanoic acid (20:5 n-3) (17.6\%) and palmitic acid (16:0) (10.3\%). The presence of polyunsaturated fatty acids in the oil, especially long chain compounds such as eicosapentaenoic acid, may explain its anti-inflammatory properties (9).

\section{Development of bullfrog oil-based nanoemulsions}

In this work, an innovative bullfrog oil based nanoemulsion with higher oil concentration $(14 \%(\mathrm{~m} / \mathrm{m}))$ and lower concentration $(6 \%, \mathrm{~m} / \mathrm{m})$ of nonionic surfactants (Tween ${ }^{\circledR} 20 /$ $\operatorname{Span}^{\circledR} 8063$ : 37) was produced. Later on, this control nanoemulsion was optimized by a 
$2^{3}$ full-factorial experimental design to obtain the therapeutic oral bullfrog oil-based nanoemulsion containing different pharmaceutical excipients.

The control bullfrog oil based nanoemulsion showed a milky single-phase system due to the decrease of surface tension by the surfactant mixture. Conductivity was $149.6 \pm 2.9$ $\mu \mathrm{S} \mathrm{cm}-1$ due to the ions present in the continuous aqueous phase of the $\mathrm{O} / \mathrm{W}$ nanoemulsion. This nanoemulsion showed a neutral $\mathrm{pH}$ of $6.6 \pm 0.01$. These parameters can influence the charge, solubility, partitioning, oxidative reactions, and chemical stability of compounds (17). An increase of primary oxidation products (peroxides) was observed in the nanoemulsions stabilized with Tween 80 and sodium dodecylsulfate when decreasing the $\mathrm{pH}$ of the nanoemulsion. In addition, a low $\mathrm{pH}$ could promote the activation of metal ions responsible for promoting the oxidation process (18).

The droplet size of the control nanoemulsion was $304.6 \pm 22.4 \mathrm{~nm}$ with PDI of $0.314 \pm$ 0.125 . Droplet size is a crucial factor for monitoring nanoemulsion stability. In general, smaller droplet size produces more stable nanoemulsions, and with many sites for gastric lipase binding, improve the fat digestion rate (19). The nanoemulsion zeta potential was -17.2 \pm 0.1 , suggesting that repulsive forces predominated over the attractive ones.

\section{Optimization of the therapeutic oral bullfrog oil based nanoemulsion}

According to the results obtained for the control nanoemulsion, optimization of the pharmaceutical excipients used to obtain the therapeutic oral bullfrog oil based nanoemulsion was carried out. Three excipients at fixed concentrations, $(5 \%(\mathrm{~m} / \mathrm{m})$ propylene glycol, $0.3 \%(\mathrm{~m} / \mathrm{m})$ xanthan gum and $0.01 \%(\mathrm{~m} / \mathrm{m}) \mathrm{BHT})$ and a different composition of flavoring $(\mathrm{x} 1)$, sweetener $(\mathrm{x} 2)$ and preservative $(\mathrm{x} 3)$, were added to the control bullfrog oil based nanoemulsion in order to produce the therapeutic oral nanoemulsion (Table I). The aforementioned fixed pharmaceutical excipients were used at a concentration approved for oral pharmaceutical products (20). Propylene glycol acts on the solubility and dispersion of active substances, and it can also create a stable homogeneous nanoemulsion (20). Xanthan gum is an anionic heteropolysaccharide applied to enhance the viscosity of the continuous phase in the $\mathrm{O} / \mathrm{W}$ nanoemulsion, decreasing the droplet movement and diffusion of pro-

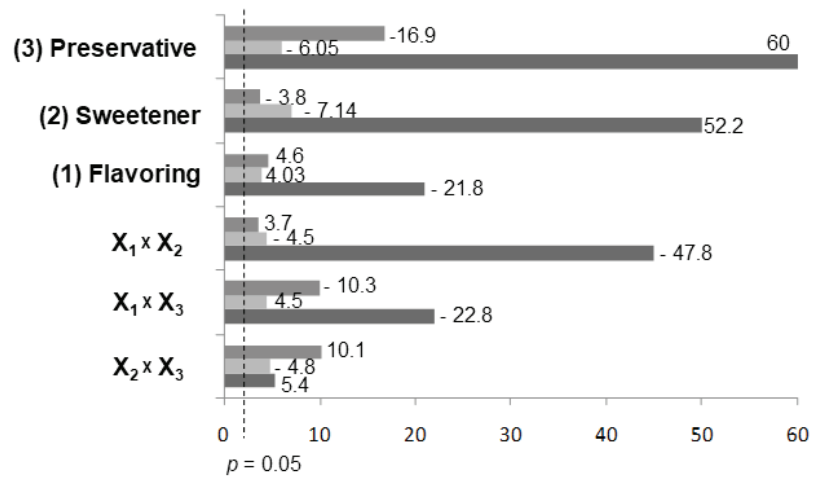

Fig. 1. Pareto Chart of the standardized effects on droplet size (匹), zeta potential $(\varpi)$ and $\mathrm{pH}(\square)$ in the formation of bullfrog oil nanoemulsions. 
oxidants responsible for the creaming and lipid oxidation $(21,22)$. BHT is a highly effective synthetic antioxidant used to control lipid oxidation (14). Nonpolar antioxidants tend to get localized in the oil phase and the interfacial layer, increasing its effectiveness to retard oil oxidation $(14,18)$. A previous study has also shown the BHT ability to delay bullfrog oil oxidation (7).

The experimental design approach was, therefore, applied to determine the best combination of flavoring, sweeteners and preservatives to produce a stable oral nanoemulsion. All the oral nanoemulsions showed a homogeneous milky aspect, and the absence of bullfrog oil smell. The mean hydrodynamic diameter was strongly influenced by the selected variables, emphasizing their relevancy as critical parameters that would influence the preparation process. The oral nanoemulsion size ranged from 300 to $470 \mathrm{~nm}$. The Pareto chart gives standardized effects of the independent variables and their interactions with the dependent variable (Fig. 1).

The Pareto chart allows identification of the statistically significant variables needed to produce the nanoemulsion. Thus, the individual standardized effects of the studied variables and, later, their interaction effects on the size, zeta potential, and $\mathrm{pH}$ were analyzed. Positive value of the response of independent variables indicates an unfavorable increase in droplet size, or a favorable effect on the increase of the zeta potential and the $\mathrm{pH}$ value. Therefore, all first order independent variables had a significant effect on the droplet size, especially the preservative ingredient $(p<0.05)$. Effects of the preservative and sweetener ingredients, and their interactions, were the ones that most significantly influenced the formation of smaller droplet size. Sodium benzoate, when used as a preservative, is an amphiphilic excipient that can act as a small chain surfactant in the nanoemulsion interface responsible for the formation of smaller droplet size (23). According to Hatzopoulous, its chemical arrangement has an important effect on the nanoemulsion structure, promoting the formation of cylindrical/ellipsoidal droplets (23). The sucralose sweetener already contains hydroxyls groups that may confer an emulsifying action, indicating its tendency to be arranged in the droplet interface and improving its properties associated with the perception of sweetness (24).

Independent variables and their interactions were evaluated by the coefficient of determination $\left(R^{2}\right)$, which represents the linear relationship between the observed and the predictive values. Thus, the matrix of the developed experiments was considered statistically significant with a linear relationship of $R^{2}=0.972$, indicating that the model could explain $97.2 \%$ of the variability in the obtained response. The adjusted determination coefficient $\left(R_{\text {Adj }}^{2}\right) 0.959$ confirmed the high significance of the model to droplet size analyses of the nanoemulsion. Therefore, this matrix of experiments ensured satisfactory adjustment of the linear model to experimental data.

Aiming at straightforward examination of experimental variables in the responses, the three-dimensional response surfaces were drawn. Figures $2 \mathrm{a}$ and $2 \mathrm{~b}$ show a three-dimensional diagram of the droplet size response surface relating to both the preservative and the sweetener (Fig. 2a), and the preservative and the flavoring (Fig. 2b). As can be seen, reduction of the droplet size can be achieved at a low level of flavoring and a high level of preservative and sweetener. Therefore, nanoemulsions with smaller droplet sizes were obtained with $0.2 \%(\mathrm{~m} / \mathrm{m})$ of sodium benzoate and $0.02 \%(\mathrm{~m} / \mathrm{m})$ of propylparaben as preservatives, $0.1 \%(\mathrm{~m} / \mathrm{m})$ of sucralose and $0.4 \%(\mathrm{~m} / \mathrm{m})$ of acesulfame K as sweetener; and 0.1 $\%(\mathrm{~m} / \mathrm{m})$ of tutti-frutti as flavoring. 
a)

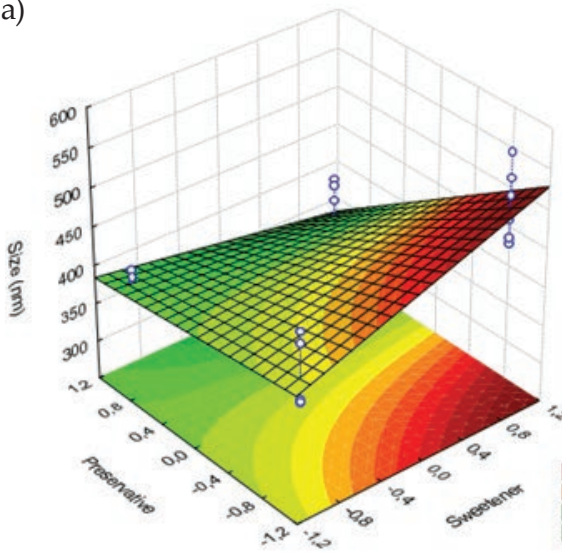

c)

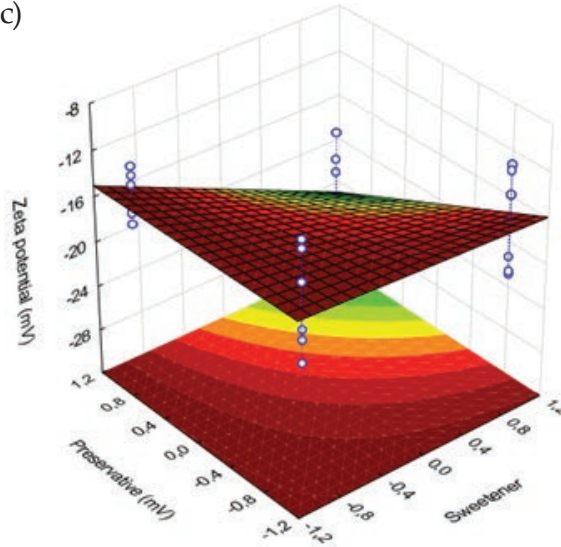

e)

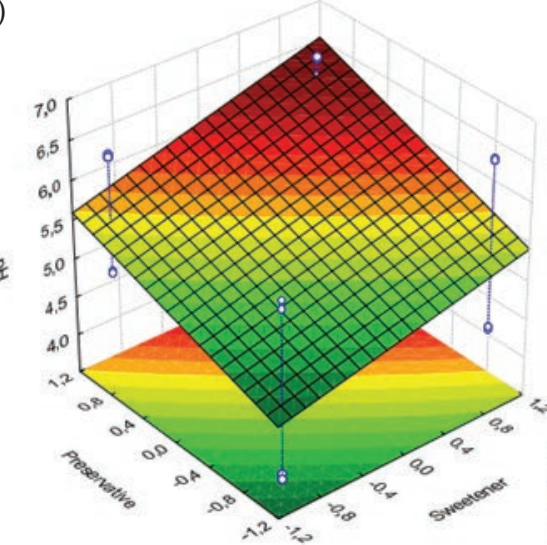

b)

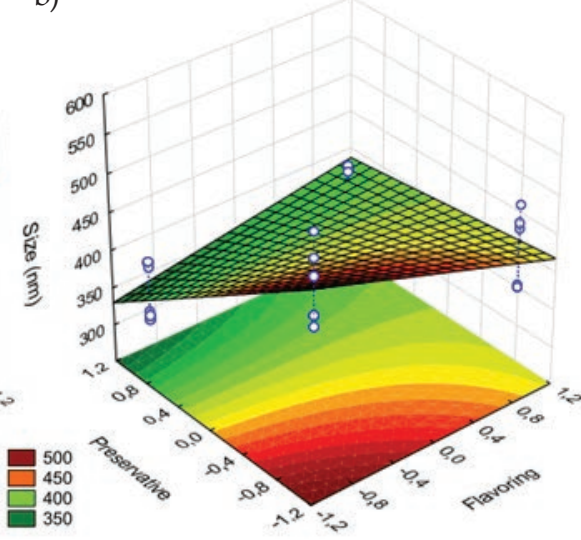

d)

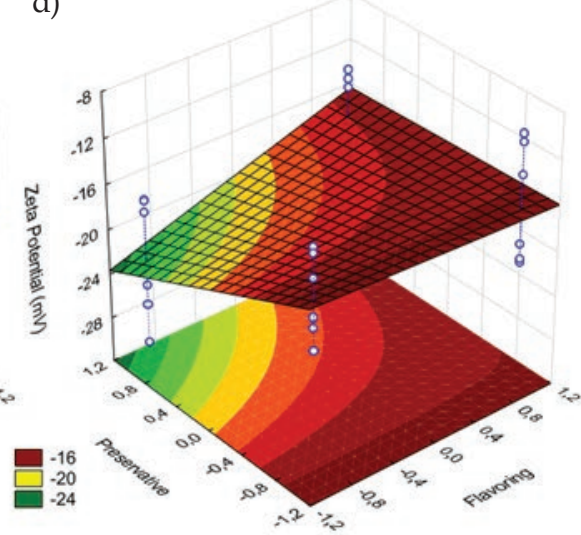

f)

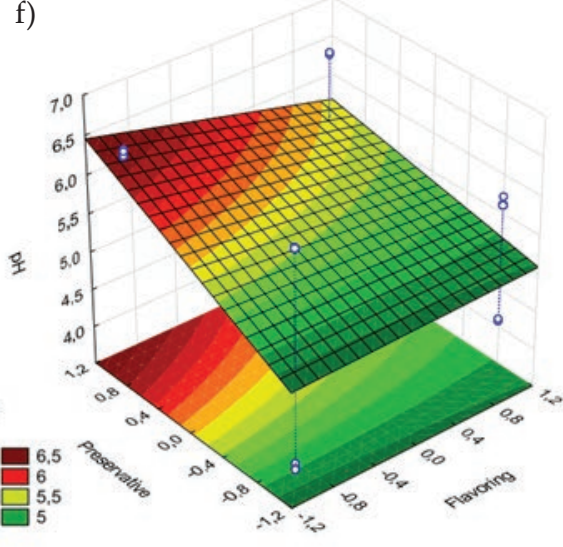

Fig. 2. Effect of the interaction between independent variables (preservative $X$ sweetener, and preservative $\mathrm{X}$ flavoring) on the droplet size $(\mathrm{a}, \mathrm{b})$, zeta potential $(\mathrm{c}, \mathrm{d})$ and $\mathrm{pH}(\mathrm{e}, \mathrm{f})$. 
The zeta potential values ranged from $-14 \pm 0.8$ to $-30 \mathrm{mV} \pm 1.2$. All independent variables had a significant effect on the zeta potential $(p<0.05)$ with $R^{2}=0.93$ and $R_{\text {Adj }}^{2}=0.90$ (Fig. 1). In addition, all samples showed negatively charged droplets, which may be due to the anionic character of xanthan gum and other excipients present in the formulation (21). Higher zeta potential of the nanoemulsion was obtained at the high level $(+1)$ of sweetener and preservative, and low level (-1) of flavoring (Fig. 2c,d). Sucralose can act as a surface agent by exposing its hydroxyl and chlorine groups, contributing to the electrostatic potential near the droplet surface, jointly with the acesulfame $\mathrm{K}$ and sodium benzoate (24). Thus, the use of an ideal pharmaceutical adjuvant may increase the ionic strength in the aqueous phase of the $\mathrm{O} / \mathrm{W}$ nanoemulsion, affecting the electrostatic repulsion between the dispersed droplets and increasing the electrostatic stability of the colloidal dispersion.

The $\mathrm{pH}$ values were significantly influenced by all independent variables according to the Pareto diagram (Fig. 1) with ANOVA linear relation with $R^{2}=0.99$ and $R_{\text {Adj }}^{2}=0.99$. Preservatives and sweeteners had a significant effect on $\mathrm{pH}$ increase. In contrast, a low level of flavorings generated nanoemulsions with low $\mathrm{pH}$ values. Some citrus flavorings, such as pineapple flavor, are composed of chemically unstable esters that are prone to degradation during storage, thereby decreasing the $\mathrm{pH}$ of the nanoemulsion (3). The response surface of interactions between the independent variables (Fig. 2e,f) showed that neutral $\mathrm{pH}$ values for the oral bullfrog oil based nanoemulsion were obtained with high levels of preservative and sweetener, and a low level of flavoring.

When all dependent variables were taken together, the optimal composition of the oral nanoemulsion would contain $0.2 \%(\mathrm{~m} / \mathrm{m})$ of sodium benzoate and $0.02 \%(\mathrm{~m} / \mathrm{m})$ of propylparaben as preservatives, $0.1 \%(\mathrm{~m} / \mathrm{m})$ of sucralose and $0.4 \%(\mathrm{~m} / \mathrm{m})$ of acesulfame K as sweeteners, and $0.1 \%(\mathrm{~m} / \mathrm{m})$ of tutti-frutti as flavoring. The oral bullfrog oil based nanoemulsion prepared under these conditions showed a final droplet size of $410 \pm 8 \mathrm{~nm}$, PDI of $0.20 \pm 0.02$, zeta potential of $-38 \pm 2.5 \mathrm{mV}$, pH of $6.43 \pm 0.05$ and conductivity of $1913.8 \pm$ $3.15 \mu \mathrm{S} \mathrm{cm}{ }^{-1}$, indicating favorable properties for oral application.

\section{Stability of the optimized oral nanoemulsion}

Stability determination of the optimized oral nanoemulsion was important to assess the effect of pharmaceutical excipients on the formulation. The control nanoemulsion without excipients showed a creaming index of $3.2 \%$ and phase separation after 60 and 19 days when stored at 25 and $45^{\circ} \mathrm{C}$, respectively. The optimized oral nanoemulsion showed a milky single phase; fishy smell reduction, higher viscosity and physical stability at $25^{\circ} \mathrm{C}$. This effect can be associated with xanthan gum, which increases the viscosity of the aqueous phase, reducing the coalescence of oil droplets from the oral nanoemulsion (21).

The preliminary stability study allowed possible detection of short-time physical instabilities in the control nanoemulsion, indicating the need for reformulation. The optimized oral bullfrog oil based nanoemulsion showed no visible creaming or phase separation after centrifugation. However, the control nanoemulsion showed phase separation in the second freeze/thaw cycle, while the optimized oral nanoemulsion remained stable after 6 cycles, indicating that the presence of excipients improved its physical stability.

Influence of excipients on the $\mathrm{pH}$ and droplet size was investigated in control and optimized oral bullfrog oil based nanoemulsions (Fig. 3). After 90 days, the optimized oral nanoemulsion showed no significant difference in the $\mathrm{pH}$ value, $\mathrm{pH}$ of $6.43 \pm 0.1$, indicating 
that the excipients were responsible for promoting good physicochemical stability (Fig. 3a). However, a significant $\mathrm{pH}$ change from $6.68 \pm 0.01$ to $2.97 \pm 0.01$ for the control nanoemulsion was observed. This effect can be explained by the fatty acid hydrolysis of bullfrog oil or by microbiological proliferation in the nanoemulsion (25). The oral nanoemulsion containing excipients showed a superior droplet size $(410 \pm 8 \mathrm{~nm})$ compared to that of the control nanoemulsion ( $305 \pm 13 \mathrm{~nm}$ ) (Fig. 3b). However, the droplet size of the oral nanoemulsion containing excipients remained constant during the storage period at $25^{\circ} \mathrm{C}(p>$ 0.05), with lower PDI value ranging from 0.2 to 0.3 , whilst the control nanoemulsion showed a higher value (ranging from 0.3 to 0.6 ). Multimodal droplet size distributions can be responsible for the instability of the basic nanoemulsion after storage due to the coalescence of droplets (26).

Zeta potential is a stability-related parameter that measures the repulsion or attraction magnitude of the electric charges at the interface of nanoemulsion droplets (3). Optimized oral bullfrog oil based nanoemulsion showed a high zeta potential ranging from $-38 \pm 2.5$ $\mathrm{mV}$ to $-30 \pm 0.3 \mathrm{mV}$ after storage for 90 days. Although the nonionic surfactants used do not supply electrical charge to the oil droplet surface, the high initial zeta potential can be attributed to the presence of negatively charged xanthan gum, sucralose hydroxyl groups, and the presence of anionic free fatty acids from bullfrog oil $(21,27)$. In addition, owing to steric contribution of the compounds, they may also reduce droplet aggregation $(21,22,28)$. Addition of pharmaceutical excipients also increased to $1913.83 \pm 3.15 \mu \mathrm{S} \mathrm{cm}^{-1}$ the conductivity of the oral bullfrog oil-based nanoemulsion compared to the control nanoemulsion, which showed a value of $149.6 \pm 2.9$. In addition, no statistically significant difference was observed in the optimized oral nanoemulsion after storage time at $25{ }^{\circ} \mathrm{C}$.

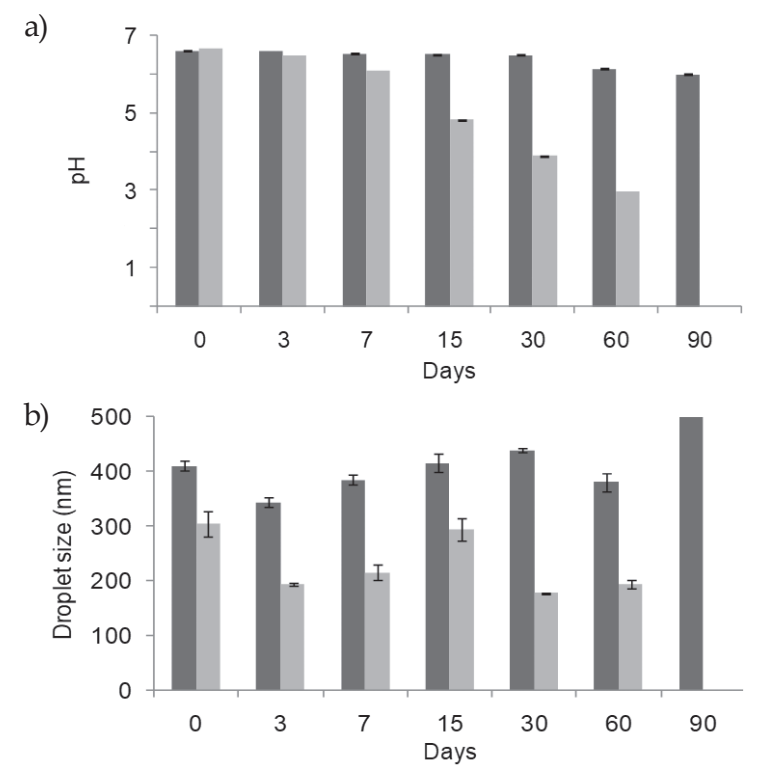

Fig. 3. a) $\mathrm{pH}$ and b) droplet size of the optimized oral (grey) and the control (light grey) nanoemulsion during 90 days of storage at $25^{\circ} \mathrm{C}$. 
a)
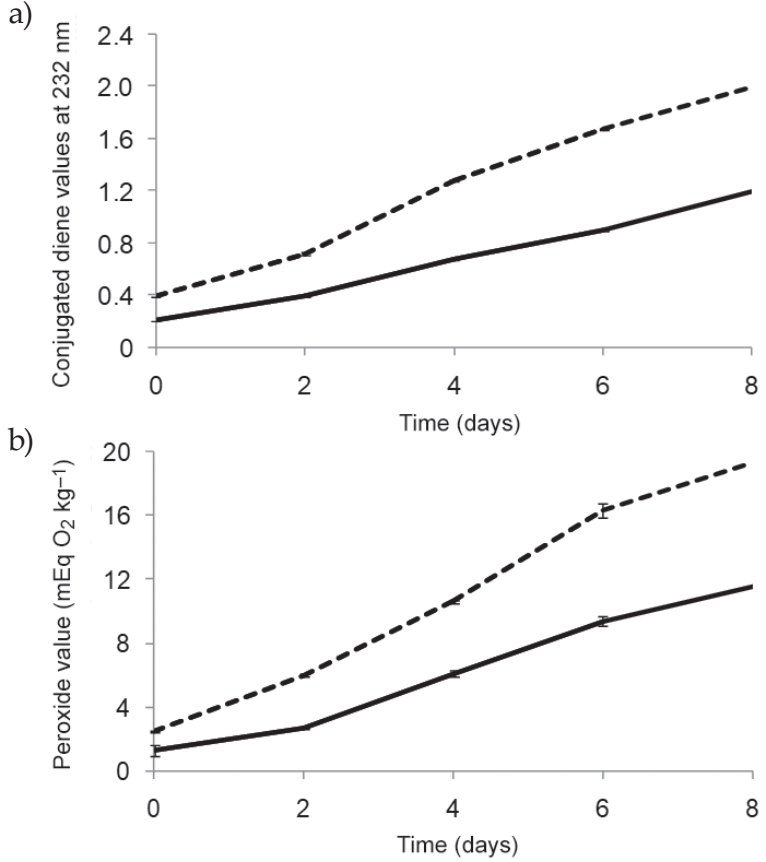

Fig. 4. a) Conjugated diene values at $232 \mathrm{~nm}$ and b) peroxide values under the Schaal oven test for the optimized oral (-) and the control (----) nanoemulsion.

Primary oxidation products were evaluated by the conjugated dienes and the peroxide value, immediately after production, and under the Schaal oven conditions at $60^{\circ} \mathrm{C}$. The optimized oral nanoemulsion showed conjugated dienes and peroxide value of $0.211 \pm$ 0.001 and $1.5 \pm 0.3 \mathrm{mEq} \mathrm{O}_{2} \mathrm{~kg}^{-1}$, respectively. However, the control nanoemulsion showed values of $0.393 \pm 0.004$ and $2.5 \pm 0.1 \mathrm{mEq} \mathrm{O}_{2} \mathrm{~kg}^{-1}$, respectively. All nanoemulsions showed an increase in the peroxide and conjugated dienes, indicating primary oxidative degradation of the bullfrog oil during storage (Fig. 4). This oxidation effect was two-fold higher for the control nanoemulsion. Addition of excipients in the optimized oral nanoemulsion was responsible for a significant decrease of the oxidation process compared to the control nanoemulsion $(p<0.05)$. The oxidation mechanism of polyunsaturated fatty acids in the nanoemulsion can be associated with the large oil droplet surface, which increases interactions between the lipids and pro-oxidant compounds from the aqueous phase (14). In general, nonpolar antioxidants such as BHT are effective in retarding oxidation in the nanoemulsion due to their localization in the oil-water interface reducing the formation of primary oxidation products (29). In addition, xanthan gum can act so as to reduce the lipid oxidation rate in the nanoemulsion interface due to its function of chelating metal ions, increasing the viscosity of the aqueous phase and delaying diffusion of pro-oxidant molecules (oxygen or metals) in the oily phase (22).

Oxidation induction time by Rancimat ${ }^{\circledR}$ was also applied to evaluate the oxidative stability of emulsified bullfrog oil. Control and optimized oral nanoemulsions showed an 
induction time of $0.25 \pm 0.01$ and $6.69 \pm 0.15$ hours, respectively. Pharmaceutical excipients increased 27-fold the oxidative stability of the optimized oral bullfrog oil-based nanoemulsion, preventing oxidation of unsaturated fatty acids from bullfrog oil. This result corroborates the ones of Sotomayor-Gerding et al., who observed a 22-fold increase of the induction time in the linseed oil-loaded nanoemulsion with astaxanthin and lycopene compared to the control nanoemulsion (30).

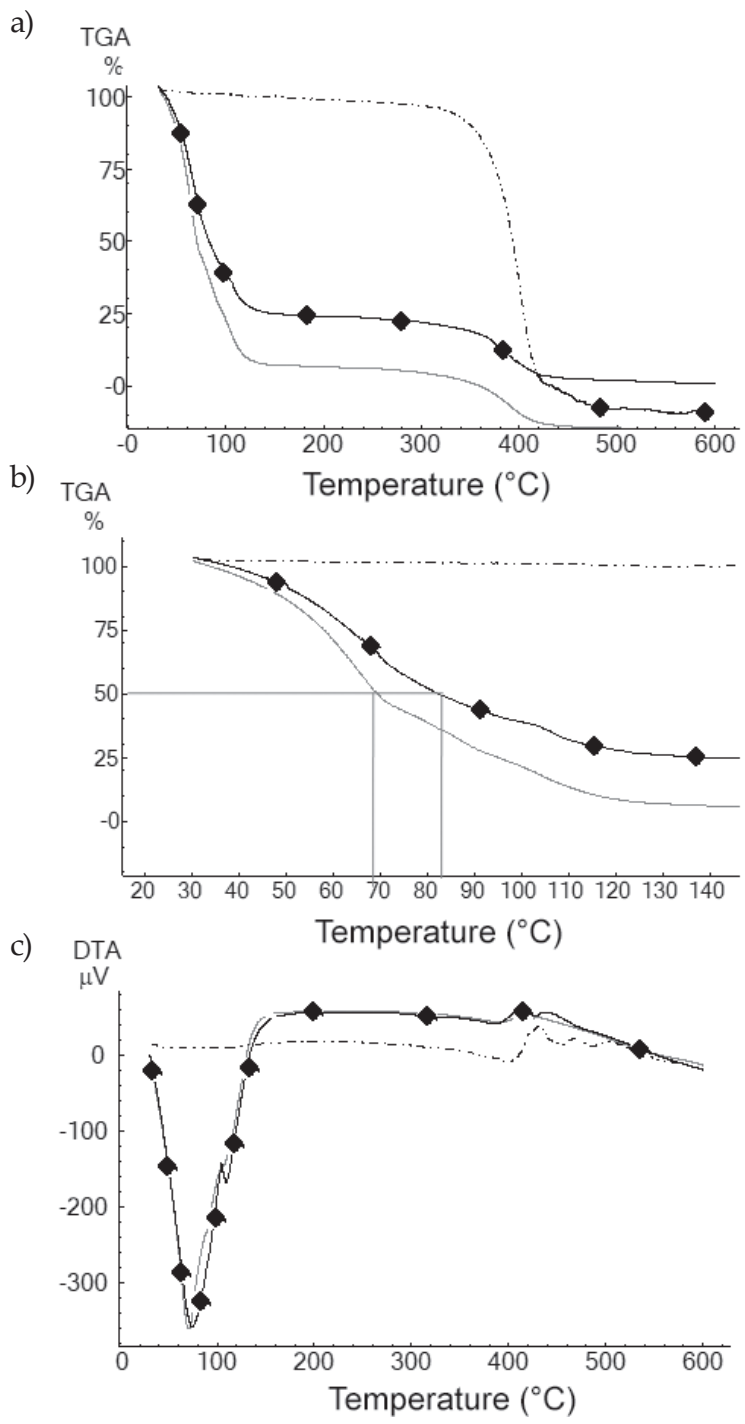

Fig. 5. TGA (a, b) and DTA (c) curves of nanoemulsions. Samples: (----) bullfrog oil, (- $\bullet$ ) oral nanoemulsion, and (-) control nanoemulsion. 
As seen in Fig. 5a, the TGA profiles of the control and the optimized oral nanoemulsion were divided into two mass loss events. The temperature range used in the thermal stability analyses was selected according to the TGA curve of bullfrog oil, which showed thermal decomposition products with total mass loss up to $530^{\circ} \mathrm{C}(7)$. The first weight loss event occurred up to $135{ }^{\circ} \mathrm{C}$, with a loss of 93 and $73 \%$ for the control and the optimized oral nanoemulsion, respectively. The first weight loss occurred due to the evaporation of free and bound water loss with increasing temperature. The final weight change was observed above $350^{\circ} \mathrm{C}$, which implies the presence of bullfrog oil and other constituents that degraded at higher temperatures in the nanoemulsion. In addition, the control nanoemulsion showed a decomposition temperature of $50 \%$ of the sample at $68{ }^{\circ} \mathrm{C}$, while for the optimized oral nanoemulsion such temperature event was settled at $83^{\circ} \mathrm{C}$ (Fig. 5b). This behavior can be mainly attributed to the presence of different excipients in the oral nanoemulsion, indicating the best thermal performance. In differential thermal analysis (DTA), one endothermic event was observed for both oral and control nanoemulsions, ranging from 30 to $130{ }^{\circ} \mathrm{C}$. After dehydration, two successive exothermic events took place under further heating $\left(370-470{ }^{\circ} \mathrm{C}\right)$, related to the thermal degradation of pharmaceutical additives and the bullfrog oil. However, the energy release of the exothermic reaction was higher for the oral nanoemulsion, which may be due to the presence of pharmaceutical additives.

\section{CONCLUSIONS}

Bullfrog oil was efficiently extracted and showed ideal physicochemical characteristics with low peroxide and acidity values. Chemical composition of bullfrog oil shows a high predominance of eicosapentaenoic and oleic acids. The preparation process of a therapeutic oral nanoemulsion composed of bullfrog oil: Tween ${ }^{\circledR} 20 / \operatorname{Span}^{\circledR} 80 /$ water at the ratio of $14: 3.8: 2.2: 80$ by the phase inversion method was satisfactorily optimized by $2^{3}$ full factorial design. The composition of the preservatives, sweeteners and flavoring selected by the factorial design was $0.2 \%$ sodium benzoate $+0.02 \%(\mathrm{~m} / \mathrm{m})$ propylparaben, $0.1 \%$ $(\mathrm{m} / \mathrm{m})$ sucralose $+0.4 \%(\mathrm{~m} / \mathrm{m})$ acesulfame K, and $0.1 \%(\mathrm{~m} / \mathrm{m})$ tutti-frutti, respectively. Incorporation of bullfrog oil in an oral emulsified system improved its unpleasant organoleptic characteristics and increased its thermal and oxidative stability over a basic nanoemulsion. Finally, this research indicated that bullfrog oil proved to be suitable for the development of dispersed systems, due to its rich composition of bioactive compounds that allow for a probable therapeutic activity. This activity can be potentiated by the developed emulsified system, due to its capacity to improve the biopharmaceutical and pharmacokinetic properties of the oil and, in addition, masking its unpleasant organoleptic properties. It is therefore believed that such qualities of the oral bullfrog oil nanoemulsion would enhance patient compliance with the treatment.

Acknowledgement. - The authors thank CAPES and CNPQ for financial support, the Asmarana Produtos Naturais for providing the bullfrog fatty tissue, and the Laboratory of Fuels and Lubricants (UFRN) for the Rancimat ${ }^{\circledR}$ analyses. 


\section{REFERENCES}

1. J. L. Burguera and M. Burguera, Analytical applications of emulsions and microemulsions, Talanta 96 (2012) 11-20; https://doi.org/10.1016/j.talanta.2012.01.030

2. A. H. Saberi, Y. Fang and D. J. McClements, Fabrication of vitamin E-enriched nanoemulsions: Factors affecting particle size using spontaneous emulsification, J. Colloid Interface Sci. 391 (2013) 95-102; https://doi.org/10.1016/j.jcis.2012.08.069

3. D. T. Piorkowski and D. J. McClements, Beverage emulsions: Recent developments in formulation, production, and applications, Food Hydrocoll. 42 (2014) 5-41; https://doi.org/10.1016/j.foodhyd.2013.07.009

4. D. J. McClements and Y. Li, Structured emulsion-based delivery systems: Controlling the digestion and release of lipophilic food components, Adv. Colloid Interface Sci. 159 (2010) 213-228; https:// doi.org/10.1016/j.cis.2010.06.010

5. P. Karthik and C. Anandharamakrishnan, Enhancing omega-3 fatty acids nanoemulsion stability and in-vitro digestibility through emulsifiers, J. Food Eng. 187 (2016) 92-105; https://doi.org/10.1016/j. jfoodeng.2016.05.003

6. I. A. Nehdi, Characteristics and composition of Washingtonia filifera (Linden ex André) H. Wendl. seed and seed oil, Food Chem. 126 (2011) 197-202; https://doi.org/10.1016/j.foodchem.2010.10.099

7. R. Rutckeviski, F. H. Xavier-Jr, A. R. V. Morais, E. N. Alencar, L. A. Machado, J. Genre, A. Gondim and E. S. T. Egito, Thermo-oxidative stability evaluation of Bullfrog (Rana catesbeiana Shaw) oil, Molecules 22 (2017) 606; https://doi.org/10.3390/molecules22040606

8. J. R. Nelson, O. Wani, H. T. May and M. Budoff, Potential benefits of eicosapentaenoic acid on atherosclerotic plaques, Vascul. Pharmacol. 91 (2017) 1-9; https://doi.org/10.1016/j.vph.2017.02.004

9. D. S. Kelley, Modulation of human immune and inflammatory responses by dietary fatty acids, Nutrition 17 (2001) 669-673; https://doi.org/10.1016/S0899-9007(01)00576-7

10. E. Kurtys, U. L. M. Eisel, J. M. Verkuyl, L. M. Broersen, R. A. J. O. Dierckx and E. F. J. Vries, The combination of vitamins and omega-3 fatty acids has an enhanced anti-inflammatory effect on microglia, Neurochem. Int. 99 (2016) 206-214; https://doi.org/10.1016/j.neuint.2016.07.008

11. A. M. Eltweri, A. L. Thomas, M. Metcalfe, P. C. Calder, A. R. Dennison and D. J. Bowrey, Potential applications of fish oils rich in omega-3 polyunsaturated fatty acids in the management of gastrointestinal cancer, Clin. Nutr. 36 (2017) 65-78; https://doi.org/10.1016/j.clnu.2016.01.007

12. E. N. Alencar, F. H. Xavier-Jr, A. R. V. Morais, T. R. F. Dantas, N. Dantas-Santos, L. M. Verissimo, V. L. G. Rehder, G. M. Chaves, A. G. Oliveira and E. S. T. Egito, Chemical characterization and antimicrobial activity evaluation of natural oil nanostructured emulsions, J. Nanosci. Nanotechnol. 15 (2015) 880-888; https://doi.org/10.1166/jnn.2015.9187

13. L. Amaral-Machado, F. H. Xavier-Jr, R. Rutckeviski, A. R. V. Morais, E. N. Alencar, T. R. F. Dantas, A. K. M. Cruz, J. Genre, A. A. Silva-Jr, M. F. F. Pedrosa, H. A. O. Rocha and E. S. T. Egito, New trends on antineoplastic therapy research: Bullfrog (Rana catesbeiana Shaw) oil nanostructured systems, Molecules 21 (2016) 585; https://doi.org/10.3390/molecules21050585

14. D. J. McClements and E. A. Decker, Lipid oxidation in oil-in-water emulsions: Impact of molecular environment on chemical reactions in heterogeneous food systems, J. Food Sci. 65 (2000) 12701282; https://doi.org/10.1111/j.1365-2621.2000.tb10596.x

15. 'Stability testing of active pharmaceutical ingredients and finished pharmaceutical products', in 953, ed. by World_Health_Organization, 2009, pp. 1-53; http://apps.who.int/medicinedocs/documents/s19133en/s19133en.pdf; last access date June 12, 2018.

16. F. H. Xavier-Jr, K. G. H. Silva, I. E. G. Farias, A. R. V. Morais, E. N. Alencar, I. B. Araujo, A. G. Oliveira and E. S. T. Egito, Prospective study for the development of emulsion systems containing 
natural oil products, J. Drug Deliv. Sci. Technol. 22 (2012) 367-372; https://doi.org/10.1016/S17732247(12)50061-4

17. C. Jacobsen, M. B. Let, N. S. Nielsen and A. S. Meyer, Antioxidant strategies for preventing oxidative flavour deterioration of foods enriched with n-3 polyunsaturated lipids: a comparative evaluation, Trends Food Sci. Technol. 19 (2008) 76-93; https://doi.org/10.1016/j.tifs.2007.08.001

18. C. C. Berton-Carabin, M.-H. Ropers and C. Genot, Lipid oxidation in oil-in-water emulsions: Involvement of the interfacial layer, Compr. Rev. Food Sci. Food Saf. 13 (2014) 945-977; https://doi. org/10.1111/1541-4337.12097

19. M. Golding and T. J. Wooster, The influence of emulsion structure and stability on lipid digestion, Curr. Opin. Colloid Interface Sci. 15 (2010) 90-101; https://doi.org/10.1016/j.cocis.2009.11.006

20. R. C. Rowe, Handbook of Pharmaceutical Excipients, Pharmaceutical Press, London 2012; ISBN 9781 582121352 (USA)

21. V. Krstonošić, L. Dokić, P. Dokić and T. Dapčević, Effects of xanthan gum on physicochemical properties and stability of corn oil-in-water emulsions stabilized by polyoxyethylene (20) sorbitan monooleate, Food Hydrocoll. 23 (2009) 2212-2218; https://doi.org/10.1016/j.foodhyd.2009.05.003

22. K. Shimada, H. Muta, Y. Nakamura, H. Okada, K. Matsuo, S. Yoshioka, T. Matsudaira and T. Nakamura, Iron-binding property and antioxidative activity of xanthan on the autoxidation of soybean oil in emulsion, J. Agric. Food Chem. 42 (1994) 1607-1611; https://doi.org/10.1021/jf00044a004

23. M. Hatzopoulos, C. James, S. Rogers, I. Grillo, P. Dowding and J. Eastoe, Effects of small ionic amphiphilic additives on reverse microemulsion morphology, J. Colloid Interface Sci. 421 (2014) 56-63; https://doi.org/10.1016/j.jcis.2014.01.024

24. J. Marcus, S. Wolfrum, D. Touraud and W. Kunz, Influence of high intensity sweeteners and sugar alcohols on a beverage microemulsion, J. Colloid Interface Sci. 460 (2015) 105-112; https://doi. org/10.1016/j.jcis.2015.08.036

25. T. N. Barradas, V. E. B. Campos, J. P. Senna, C. S. C. Coutinho, B. S. Tebaldi, K. G. d. H. Silva and C. R. E. Mansur, Development and characterization of promising $\mathrm{o} / \mathrm{w}$ nanoemulsions containing sweet fennel essential oil and non-ionic sufactants, Colloids Surf. A Physicochem. Eng. Asp. 480 (2015) 214-221; https://doi.org/10.1016/j.colsurfa.2014.12.001

26. M. I. G. Rosas, J. M. Castro, L. A. O. Martínez, L. S. Trujillo and O. M. Belloso, Long-term stability of food-grade nanoemulsions from high methoxyl pectin containing essential oils, Food Hydrocoll. 52 (2016) 438-446; https://doi.org/10.1016/j.foodhyd.2015.07.017

27. S. Mayer, J. Weiss and D. J. McClements, Behavior of vitamin E acetate delivery systems under simulated gastrointestinal conditions: Lipid digestion and bioaccessibility of low-energy nanoemulsions, J. Colloid Interface Sci. 404 (2013) 215-222; https://doi.org/10.1016/j.jcis.2013.04.048

28. C. Arancibia, N. Riquelme, R. Zúñiga and S. Matiacevich, Comparing the effectiveness of natural and synthetic emulsifiers on oxidative and physical stability of avocado oil-based nanoemulsions, Innov. Food Sci. Emerg. Technol. 44 (2017) 8-166; https://doi.org/10.1016/j.ifset.2017.06.009

29. C. Poyato, I. Navarro-Blasco, M. I. Calvo, R. Y. Cavero, I. Astiasarán and D. Ansorena, Oxidative stability of $\mathrm{O} / \mathrm{W}$ and W/O/W emulsions: Effect of lipid composition and antioxidant polarity, Food Res. Int. 51 (2013) 132-140; https://doi.org/10.1016/j.foodres.2012.11.032

30. D. S. Gerding, B. D. Oomah, F. Acevedo, E. Morales, M. Bustamante, C. Shene and M. Rubilar, High carotenoid bioaccessibility through linseed oil nanoemulsions with enhanced physical and oxidative stability, Food Chem. 199 (2016) 463-470; https://doi.org/10.1016/j.foodchem.2015.12.004 